\title{
Dry fruit as source of fungal contaminants or functional compounds?
}

\author{
Naralice HARTWIG ${ }^{1}$, Cláudia Fetter Jorge FERREIRA ${ }^{1}$, Carolina Carvalho COLAZZO ${ }^{1}$, Larine KUPSKI ${ }^{1 *}$ (D), \\ Eliana BADIALE-FURLONG ${ }^{1}$
}

\begin{abstract}
This study evaluated the role of dry fruits as a source of fungal contaminants or functional compounds. Dry apple, apricot, candied fruits, prune, and white and black raisin were evaluated regarding patulin and ergosterol content, centesimal composition, $\mathrm{pH}$, acidity, pectin, and phenolic profile. The ergosterol was detected in 38\% of the samples and patulin (PAT) in $89 \%$, the apricot samples stood out most by contaminant level. Apricot, candied fruit, and prunes presented moisture values beyond the other dry fruits. The $\mathrm{pH}$ ranged from 3.8 to 4.6 ; acidity from 0.1 to $1.0 \%$; sugar content from 1.7 to $5.5 \%$; and levels of soluble and insoluble pectin from 1.6 to $5.1 \%$ and $10.9 \%$ to $27.3 \%$, respectively. The apples showed a higher content of free phenolic compounds (6.6 mg of gallic acid/g) with a predominance of gallic and protocatechuic acids. Pearson's correlation showed a significant positive correlation between patulin and ergosterol content (0.99) and soluble pectin (0.78); a significant negative relation between total sugars $(-0.66)$ and free phenolic compounds $(-0.63)$. Fungal contamination and the occurrence of PAT show that this mycotoxin is present and, therefore, the evaluation of fungal toxins in dry fruits is recommended before claiming them to be a source of functional compounds.
\end{abstract}

Keywords: ergosterol; patulin; Pearson correlation; phenolic acids; pectin.

Practical Application: The study conducted in this work proves that a concern regarding the consumption of dehydrated fruits is necessary. Since they are widely consumed due to their practicality and present different levels of contamination by mycotoxin patulin.

\section{Introduction}

Dry fruits are consumed frequently due their nutritional value, practicality, durability, and high levels of functional compounds, especially pectin and phenolic acids (Fabani et al., 2017). The basic structure of phenolic compounds consists of an aromatic ring that has one or more hydroxyl groups, including other functional groups, that are responsible for their distinct physical, chemical, biological, and multifunctional properties. They are classified into flavonoids (anthocyanins, flavonols, and their derivatives) and not flavonoids (phenolic acids, their derivatives and stilbenes) (Lee et al., 2005). The phenolic acids present in vegetables have been shown to have a functional role due to their high antioxidant activity, that prevents oxidative damages and, in some cases, acting as an antifungal (Bolzan et al., 2015; Boyjoo et al., 2017; Pagnussatt et al., 2016).

Pectin is a class of carbohydrates compounded by units of galacturonic acid polymerized in soluble and insoluble forms, that promote bonding among the cell walls of the vegetable. In the diet they correspond to the fibre fraction that is classified as functional by their preventive properties against health damage. However, due to their physicochemical characteristics, dry fruits are also a good substrate for fungal growth and, if the fungi are toxigenic, they may produce mycotoxins (Ji et al., 2017).
Mycotoxins are secondary metabolites produced by toxigenic fungi that can contaminate raw materials in the field or in post-harvest, under the right conditions of temperature, moisture, and quantity of nutrients, specific for each fungal species (Sweeney \& Dobson, 1998). The most commonly detected mycotoxins in fruits is Patulin (PAT) (4-hydroxy-4H-furo [3,2-c] pyran-2 $(6 \mathrm{H})$-one) produced by some species of fungi, such as Penicillium expansum, Aspergillus clavatus, and Byssoclhamys nivea. PAT can cause damage to kidneys, liver, intestinal tissue, and the immune system (Speijers et al., 1988; Wichmann et al., 2002). It was also found in the literature that it is genotoxic, carcinogenic type III, embryotoxic, and teratogenic (Alves et al., 2000; Ciegler et al., 1976; Liu et al., 2003; Osswald et al., 1978; Smith et al., 1993).

PAT has been researched mainly in fresh apples and apple products (Murillo-Arbizu et al., 2009; Welke et al., 2009) and is poorly investigated in dry fruits (Ji et al., 2017). The increasing consumption of dry fruits makes it important to investigate their chemical, functional, and mycotoxicological characteristics (regarding the presence of ergosterol and PAT). In this work the objective was to evaluate the role of dry fruits (apples, apricots, candied fruits (CF), prunes, and black and white raisins) as a source of fungal contaminants or functional compounds, aiming to provide suggestion subsidies to better define the risk benefit of their consumption in human diet. 


\section{Materials and methods}

\subsection{Standards and reagents}

The standard of PAT and phenolic acids (gallic, protocatechuic, chlorogenic, hydroxybenzoic, caffeic, syringic, coumaric, ferulic, and vanillin acids) were purchased from Sigma Aldrich (USA). The major reagents and solvents employed in the experiments were: HPLC grade ethyl acetate (Vetec Chemistry, Brazil), sodium acetate (Vetec Chemistry, Brazil), acetic acid (Merck, Germany), acetone (Neon Comercial Ltda), acetonitrile, ultrapure water obtained in the Direct-Q UV3 Millipore system $(18.2 \mathrm{M} \Omega \mathrm{cm}$ resistivity), Folin Ciacalteau $2 \mathrm{~N}$ reagent (Proton Chemistry, Brazil), ethanol (JT Baker, USA), and Sodium Sulphate (Vetec Química, Brazil).

\subsection{Samples}

Three collections from different lots of the same commercially available fruit brand were obtained from the southern region of Brazil, in the winter of the year 2016. To compose the crude sample $(10 \%$ of the available quantity of the lot in the shop: 6 to 10 packs with $250 \mathrm{~g}$ ). Each lot of the same fruit and different brand was homogenized to compose a laboratory sample (5\%). In total, 29 analytical samples were prepared: apple (5), apricot (3), candied fruits (6 that were a mix of papaya and orange), prune (7), white raisin (3), and black raisin (5). All samples were within the expiration date and each lot of the same fruit had a similar manufacturing date. Samples, homogenized by groups, were stored under refrigeration conditions $\left(5^{\circ} \mathrm{C}\right)$ until use.

\subsection{Fungal contamination}

\section{Ergosterol}

Ergosterol determination was carried out according to the modified method of (Gutarowska \& Zakowska, 2009) in HPLC-UV (Freitas et al., 2016) to indicate fungal contamination.

\section{Patulin}

PAT standard was purchased from Sigma Aldrich (USA). The stock solution was prepared by dilution of $5 \mathrm{mg}$ PAT in $25 \mathrm{~mL}$ of ethyl acetate grade HPLC, which formed the stock solution. To prepare the working solution $1 \mathrm{~mL}$ of the stock one was transferred to a $10 \mathrm{~mL}$ flask. The standard was dried in the flask and subsequently resuspended with ethanol grade HPLC. The solution concentration was confirmed spectrophotometrically, by considering the molar absorptivity of $14600 \mathrm{~mol} / \mathrm{cm}$ in ethanol at $276 \mathrm{~nm}$. This work solution was used to prepare the standard ones for the calibration curve.

To determine the mycotoxin, was employed an HPLC-UV equipped with a UV detector and Gemini C18 analytical column $(250 \mathrm{~cm} \times 4.6 \mathrm{~mm} \times 5 \mu \mathrm{m})$. The mobile phase was $\mathrm{H}_{2} \mathrm{O}$ :acetonitrile ratio of $90: 10 \mathrm{v} / \mathrm{v}$, flow rate of $0.8 \mathrm{~mL} / \mathrm{min}$, and a detection wavelength of $276 \mathrm{~nm}$. The instrument limit of detection (LODi) and limit of quantification (LOQi) were determined as the lowest injected PAT concentrations that yielded signal-to-noise $(\mathrm{S} / \mathrm{N})$ ratios of 3 and 10 , respectively. The analytical curve ranged from 5 to $144 \mathrm{ng} / \mathrm{mL}$.
The moisture of the dry fruit samples were adjusted to $50 \%$ by adding deionized water to complete the difference from the original content (22 to 36\%). The QuEChERS method, described by Azaiez et al. (2014), was carried out by weighing $5 \mathrm{~g}$ of the wet samples. First it was tested with different extractor solvents: acetonitrile:water solution $(75 / 25$, v/v) with $1 \%$ acetic acid (first experiment); ethyl acetate (second experiment); ethyl acetate:water solution $(90: 10, \mathrm{v} / \mathrm{v})$ with $1 \%$ acetic acid (third experiment); and ethyl acetate:water solution $(60: 40, \mathrm{v} / \mathrm{v})$ with $1 \%$ acetic acid (fourth experiment).

Then, $30 \mathrm{~mL}$ of the extractor mixture, $7.5 \mathrm{~g}$ of sodium sulphate anhydrous and $3 \mathrm{~g}$ of sodium acetate anhydrous were added. In each step the mixture (sample:extractor) was vortexed for $3 \mathrm{~min}$ and, after, underwent continuous mechanic shaking $(1 \mathrm{~h})$. The samples were centrifuged for $10 \mathrm{~min}$ at $4820 \mathrm{xg}$ at $5{ }^{\circ} \mathrm{C}$. An aliquot $(10 \mathrm{~mL})$ of the supernatant layer was collected and dried under nitrogen stream. The dry extracts were dissolved in their mobile phase and PAT was determined in HPLC-UV, according to the chromatographic conditions established before. The efficiency of each extraction solvent was evaluated by comparison of PAT recovery and repeatability.

The best extraction condition (third experiment) was carried out to validate PAT determination, with the black raisin sample chosen as a model because it was the matrix in which interference (colour pigments and sugar) was more probable. It was performed by the limits of quantification (LOQ), accuracy (recovery), precision (repeatability), and the matrix effect (European Comission, 2006).

The accuracy (recovery) was performed by fortifying the sample homogenized with PAT standard solution in three concentration levels $(9.5,19.0$, and $38.1 \mathrm{ng} / \mathrm{g})$. To evaluate PAT recovery from the other fruit samples, they were fortified at the intermediate level (19.0 ng/g). Repeatability was performed by the adapted QuEChERS method and carried out in samples contaminated by three levels of PAT, as a triplicate, and each level was injected three times. The RSD (\%) was calculated from nine determinations. The matrix effect on PAT determination was also assessed by relating the declivities of matrix curve (obtained by addition of increasing concentrations of PAT varying from 5 to $144 \mathrm{ng} / \mathrm{mL}$ ) and the standard curve in solvent was at the same concentration range. All the homogenized dry fruit samples were submitted to the established procedure. The identity of the contaminant in the samples was obtained by the retention time and co-chromatography with standard addition. When there was a matrix effect above the recommendation the matrix curve was adopted to quantify the contaminant in the fruit sample.

\subsection{Physico-chemical characterization of the dehydrated fruits}

The dry fruits were triturated in a blender until a homogeneous paste was obtained. The moisture determination (No. 935.29) was performed according to (Association of Official Analytical Chemists, 2000). Then, $\mathrm{pH}$ and total acidity were tested according to the potentiometric method described by (Busca et al., 2008). Total sugar was determined by the sulfuric phenol method (DuBois et al., 1956). Soluble and insoluble pectin were determined according to Bustos et al. (2014), with modifications. 
The insoluble pectin was determined in each $5 \mathrm{~g}$ of homogenized sample dissolved in $12.5 \mathrm{~mL}$ of $95 \%$ ethyl alcohol assisted by an ultrasonic probe at $60 \mathrm{~Hz}$ for $10 \mathrm{~min}$. After $30 \mathrm{~min}$ at $4{ }^{\circ} \mathrm{C}$ the content was centrifuged at $3870 \mathrm{xg}$ for $20 \mathrm{~min}$. Then, $5 \mathrm{~mL}$ of $75 \%$ ethanol was added and centrifuged again. The procedure was repeated twice more by homogenizing the supernatants. The residue was transferred to a glass beaker and $40 \mathrm{~mL}$ of distilled water was added, adjusting the $\mathrm{pH}$ to 11.50 with $1.0 \mathrm{~N} \mathrm{NaOH}$. After $30 \mathrm{~min}$ at $4{ }^{\circ} \mathrm{C}$, the content was acidified to $\mathrm{pH} 5.0$ with acetic acid solution $(1: 3 \mathrm{v} / \mathrm{v})$. The content was filtered and oven dried with air circulation at $70^{\circ} \mathrm{C}$ until a constant weight. The soluble pectin was determined from the precipitate of the insoluble pectin by adding $100 \mathrm{~mL}$ of acetone with subsequent filtration and drying over at $70{ }^{\circ} \mathrm{C}$ until a constant weight.

\subsection{Determination of Phenolic Compounds (PC)}

The free PC were extracted with methanol assisted by an ultrasonic probe and quantified after reduction of a Folin reagent in a spectrophotometer at a wavelength of $750 \mathrm{~nm}$ using a standard curve of gallic acid ( 1 to $14.5 \mu \mathrm{g} / \mathrm{mL}$ ) (Souza et al., 2009). The phenolic acid (PA) profiles of the dehydrated fruits where determined in HPLC-UV using the extract obtained from the determination of free phenolic compounds. Elution by the Supelco C18 column $(150 \times 4.6 \mathrm{~mm}$ i.d $10 \mu \mathrm{m})$ was performed at $35^{\circ} \mathrm{C}$ with methanol: water acidified with $1 \%$ acetic acid (20:80) at a flow rate of $0.7 \mathrm{~mL} / \mathrm{min}$. The detection was made in a UV detector at $280 \mathrm{~nm}$ for up to $15 \mathrm{~min}$, with a change to $230 \mathrm{~nm}$ up to $25 \mathrm{~min}$, according to Scaglioni et al. (2014). The identification of the phenolic acids was confirmed by comparing the retention times and co-chromatography with the standards.

\subsection{Statistical analysis}

Statistica 5.0 Portable program was used to carry out the statistical analyses, at a 95\% level of confidence. Multivariate analysis was performed by Pearson correlation using the statistical program PAST, to evaluate the relation among nutritional and/or functional compounds and contaminants.

\section{Results and discussion}

\subsection{Mycotoxicological contamination of dry fruits}

In order to determine PAT, in other samples beyond apple products the QuEChERS method, which was initially developed by Azaiez et al. (2014), was adapted to determine 11 mycotoxins in fruit. This choice is justified by the similarity of the matrices evaluated by the authors and the benefits of the QuEChERS procedure, with such a lower consumption of time and wastes residues, good analytical performance, and a lesser exposure for the analyst (Anastassiades et al., 2003).

The official methods (Association of Official Analytical Chemists, 2000), that are frequently applied to PAT determination, were developed for apple products, in which ethy-acetate is applied as a solvent producing a great amount of residual wastes. The challenge was that the QuEChERS method, developed by Azaiez et al. (2014), employed acetonitrile as an extractor solvent of the mycotoxins, as with other authors that adopted this procedure before. The black raisin sample was chosen to validate the adapted method, since it is, among the fruits under study, the one which is more probable to possess interference (carbohydrates and pigments) that could be difficult to recover with QuEChERS (Anastassiades et al., 2003; Kupski \& Badiale-Furlong, 2015) and would need more steps to clarify the extract. It was shown by the results of preliminary tests (experiment 1: no detection) that acetonitrile was not able to recover PAT, however a mix of water and ethyl-acetate was more efficient (experiments: 2,3,4).

Based on these experimental data, considering the chemical properties of PAT, such as polarity, and other references (Ciegler et al., 1976; Iha \& Sabino, 2008; Ji et al., 2017), the ethyl acetate:water proportion was studied at 90:10 and 60:40. The recovery percentage and CV were $117 \pm 2 \%$ and $60 \pm 12.2 \%$ respectively. Therefore, the first proportion was chosen and tested in regard to its efficiency to recover PAT from dry fruit samples.

The recovery values were around the limits recommended by the European Community (70-120\%), except for the candied fruit samples that were around $50 \%$, which probably could be due to the heterogeneity of them. These products are processed using many kinds of fruit pulp such as papaya, orange albedo, apple, and others, beside the sugar which is used to improve the drying process. Additionally, there are distinct factors that may have affected the recovery of the analyte and also the variability.

Experiments to determinate accuracy and precision of the method of different dry fruits were estimated by analysing three replicates at one level, as well as the matrix effect (Table 1). The matrix effect is a measure more commonly evaluated in mass spectrometry determination (Rogatsky \& Stein, 2005), however, in our work, was determined by evaluating the interferences on PAT determination for each kind of fruit. Interferences may increase or decrease the signal, and the magnitude of the effect may also depend on the analyte concentration in relation to the matrix components, and these effects were observed in the dry fruit samples (Table 1). In addition, it may have, in each matrix, compounds which possess chromophores which can absorb the electromagnetic radiation at the same wavelength as PAT $(276 \mathrm{~nm})$ or elute at the same time and influence the analyte detection.

When the values for the matrix effect are between -20 and $+20 \%$, the matrix effect is considered low; if they are between -50 and $-20 \%$ or between +20 and $+50 \%$ it is considered medium. If the values found are below $-50 \%$ or above $+50 \%$, the matrix effect is considered high (Economou et al., 2009). The matrix effect of dry fruit samples showed that the dry apple

Table 1. Recovery and matrix effect with modified QuEChERS method.

\begin{tabular}{lcc}
\hline \multicolumn{1}{c}{ Samples } & Recovery (\%) & Matrix effect (\%) \\
\hline Prunes & $101 \pm 4.3$ & 30.0 \\
Dried Apricots & $114 \pm 8.8$ & -81.9 \\
Candied fruit & $40 \pm 30$ & -84.4 \\
Dried Apple & $127 \pm 2.7$ & 17.3 \\
White raisin & $117 \pm 2.0$ & -5.0 \\
Black raisin & $128 \pm 4.1$ & -87.2 \\
\hline LOD $_{m}=$ detection limit of the method; $\mathrm{LOQ}_{\mathrm{m}}=$ quantification limit of the method; \\
$\mathrm{LOD}_{\mathrm{m}}=0.3 \mathrm{ng} / \mathrm{g}$ e LOQ \\
\end{tabular}


and white raisin samples have a low matrix effect (-5 and 17\%, respectively), as a consequence of the kind of pigments and carbohydrates present in these fruits, the signal of the analyte was not affected. As opposed to the candied fruit $(-84 \%)$ and black raisin (-87\%) samples, that present high pigmentation, which can act as matrix influences on PAT recovery. Due the great differences observed among each product it was decided to quantify the mycotoxin by the matrix curve (Table 2). It is important to emphasize that due the low recovery obtained for the candied fruit it was removed of this study.

After method validation the evaluation of PAT occurrence was carried out in the dry fruits collected in the southern region of Brazil (Table 2). It is important to mention that dry fruits are very frequently used in pastry products in this region, especially in the winter - the period that was chosen to collect the samples. During the sampling it was observed that there were few brands available, the only difference was in the packing size.

In relation to fungal contaminants, the highest content of ergosterol was detected for apricot samples $(617 \mu \mathrm{g} / \mathrm{g})$ (Table 2). This allows deduction about fungal contamination, since ergosterol is an important indicator of fungal growth (Caldas et al., 2016). Caldas et al. (2011) evaluated the ergosterol content in dry fig samples and obtained values in the range of 4.5 to $18 \mu \mathrm{g} / \mathrm{g}$, which were higher in prune, candies fruit, apple, white, black raisin, and apricots found in this work. Capello et al. (2007) evaluated ergosterol content in raisins and found concentrations ranging from 0.01 to $0.6 \mu \mathrm{g} / \mathrm{g}$, results higher than those found in our work, however lower than those detected in apricot samples. It should be noted that apricot samples showed lower phenolic content than other matrices, which may be related to their observed ergosterol content (Table 3).

The survey of PAT contamination showed that $89 \%$ of the samples were contaminated, noting that apricot samples are the most contaminated products $(286 \mu \mathrm{g} / \mathrm{kg})$. In addition, this matrix also presented the highest content of ergosterol (Table 2), suggesting their susceptibility to fungal contamination.

Zouaoui et al. (2015) evaluated the contamination by PAT in 214 samples of fruit products ( 30 samples of concentrated juice, 42 samples of apple juice, 42 samples of pear juice, 34 samples of mixed juice, 15 samples of apple compote, and 16 samples of pear compote). They found that $50 \%$ of the samples were contaminated with a mean contamination of $89 \mu \mathrm{g} / \mathrm{L}$. The same kind of fruits were evaluated by Ji et al. (2017), including fresh apples and dry figs, in which contamination was found to range from 10 to $277 \mu \mathrm{g} / \mathrm{kg}$. The highest level of contamination obtained by the authors was similar to the average contamination of the apricot samples in our study.

It is important to emphasize that patulin is present in different fruit products, not only the dried fruits (evaluated in this work), as well as juices and compotes, being important the evaluation of its occurrence in different products and not only in fruits such as fresh apples.

Note that exposure to this contaminant, even at chronic levels by the direct consumption of these products, can trigger symptoms of chronic diseases (Osswald et al., 1978). Therefore, the prevention of this risk is a challenge for those responsible for food safety, especially regarding to the expansion of processed products and fresh fruits and that the allowed levels are not defined for many fruits and their derivates.

\subsection{Physical-chemical and functional characterization of dehydrated fruits}

Chemical compositions of the dry fruit samples are presented as a range of value because there a variability of larger than $10 \%$ was found among the lots of the same type of fruit (Table 4). This behaviour was expected because, beside the natural variability of fruits composition, each sample was compounded by different lots. Prune, apricot, and candied fruit samples were outside the

Table 2. Contaminants in dry fruits.

\begin{tabular}{|c|c|c|c|c|}
\hline \multirow{2}{*}{ Fruit } & \multirow{2}{*}{ Number of samples } & \multicolumn{2}{|c|}{ Patulin } & \multirow{2}{*}{ Ergosterol $(\mu \mathrm{g} / \mathrm{g})$} \\
\hline & & Occurence (\%) & Concentration $(\mu \mathrm{g} / \mathrm{kg})$ & \\
\hline Prune & 7 & 85.7 & $<$ LOQ -40 & $0.03-0.04$ \\
\hline Dried apricot & 3 & 66.7 & $<$ LOQ -482 & $0.07-1233.1$ \\
\hline White raisin & 3 & 66.7 & $<$ LOQ-29 & $0.02-0.1$ \\
\hline Black raisin & 5 & 100.0 & $5.2-49$ & nd-0.06 \\
\hline
\end{tabular}

nd = Not detected. Matrix curves: Dried apricots ( $y=18065 \mathrm{x}-490.1)$; prune $(\mathrm{y}=133.72 \mathrm{x}-610.46)$.

Table 3. Free phenolic compounds and profile of phenolic acids in dry fruits.

\begin{tabular}{|c|c|c|c|c|c|c|c|c|c|c|}
\hline Sample & $\begin{array}{c}\text { FPC } \\
(\mathrm{mg} / \mathrm{g})\end{array}$ & $\begin{array}{l}\text { Gallic } \\
(\mu \mathrm{g} / \mathrm{g})\end{array}$ & $\begin{array}{c}\text { Protocatechuic } \\
(\mu \mathrm{g} / \mathrm{g})\end{array}$ & $\begin{array}{c}\text { Chlorogenic } \\
(\mu \mathrm{g} / \mathrm{g})\end{array}$ & $\begin{array}{c}\text { Hydroxybenzoic } \\
(\mu \mathrm{g} / \mathrm{g})\end{array}$ & $\begin{array}{l}\text { Caffeic } \\
(\mu \mathrm{g} / \mathrm{g})\end{array}$ & $\begin{array}{c}\text { Syringic } \\
(\mu \mathrm{g} / \mathrm{g})\end{array}$ & $\begin{array}{l}\text { Vanillin } \\
(\mu \mathrm{g} / \mathrm{g})\end{array}$ & $\begin{array}{c}\text { Cumaric } \\
(\mu \mathrm{g} / \mathrm{g})\end{array}$ & $\begin{array}{l}\text { Total } \\
(\mu \mathrm{g} / \mathrm{g})\end{array}$ \\
\hline Plum & $1.0-5.9$ & $155-3303$ & $<$ LOQ & $<$ LOQ & 0.7 & $0.2-0.9$ & $4.2-4.4$ & $<$ LOQ & $<$ LOQ & $160-3308$ \\
\hline Apricot & $1.1-3.3$ & $99-544$ & $<$ LOQ & $1.8-47.5$ & $4.2-5.1$ & $<\mathrm{LOQ}$ & $<$ LOQ & $0.03-0.10$ & $<$ LOQ & $106-597$ \\
\hline Apple & $3.6-9.9$ & $11-407$ & $41.3-91.4$ & $<$ LOQ & $0.2-9.1$ & $2.1-21.0$ & 7.7 & $<$ LOQ & $<$ LOQ & $55-536$ \\
\hline White grape & $0.9-10.0$ & $110-234$ & $13.9-14.6$ & $<\mathrm{LOQ}$ & $<\mathrm{LOQ}$ & $<\mathrm{LOQ}$ & $<$ LOQ & 1.3 & 0.09 & $125-250$ \\
\hline Black grape & $2.4-9.3$ & $191-785$ & $<$ LOQ & $<$ LOQ & $1.5-7.8$ & $0.7-1.9$ & $<$ LOQ & $<$ LOQ & 0.9 & 193-796 \\
\hline
\end{tabular}

FPC $=$ Free phenolic compounds; LOQ = Limit of quantification. 
parameters established by Brazilian and other legislations around the world, which recommends a maximum of $25 \%$ moisture for these products (Chandra et al., 2013). The moisture values found suggest that these products are susceptible to microbial contamination, especially fungal. Prune samples presented the highest variation among moisture levels of different lots.

Pectin in dry fruits may occur naturally and/or by addition as a gelling agent during the process. The soluble pectin fraction is composed only of pectin (galacturonic acid polymerized with different levels of methyl groups), while the insoluble fraction may contain pectin, cellulose, hemicellulose, and lignin (Chen et al., 2016). Pectin can also be determined in its entirety, as assessed by Chen et al. (2014) in apple pomace and citrus peels $(16.6 \%$ and $21.9 \%$, respectively). It is noted that pectin content is higher in dehydrated fruits than in the in nature ones, which represents an interesting contribution to fibre in diets.

Regarding the soluble pectin content, the lowest percentage was found for the candied fruits $(1.6 \%)$ and the highest for the apricot samples (5.1\%). The lowest content of insoluble pectin was also found for candied fruit (10.9\%) and the highest for prunes (27.3\%). Chenna et al. (2016) determined the sugar content in apples and dry apricots, obtaining values of 2.6 and $3.0 \%$, respectively. Comparing the results obtained in our study, the apricot samples $(1.7 \%)$ presented a lower average than was verified by the authors, while apple samples (4.1\%) showed higher contents.

Dry fruits were also good sources of free phenolic compounds (Table 3), with contents varying from $1.9 \mathrm{mg} / \mathrm{g}$ (apricot) to $6.9 \mathrm{mg} / \mathrm{g}$ (apple). It is interesting to evaluate the phenolic acid profile because, among different forms of phenolic compounds, they have been shown to have the best correlation with the antioxidant and antifungal activities (Bolzan et al., 2015; Pagnussatt et al., 2016). In relation to the profile of phenolic acids, gallic acid was the one that prevailed, in frequency and concentration, followed by the protocatechuic. Comparing the values obtained in this study of free phenolic compounds with those found in bean varieties $(0.14 \mathrm{mg}$ of ferulic acid/g) studied by Bolzan et al. (2015), it can be considered that dry fruits are good sources of these functional compounds.

Chisvert et al. (2017) evaluated the total phenolic compounds in whole fresh apples and obtained an average content of $1.1 \mathrm{mg}$ gallic acid/g. The phenolic content in prune, apricot, and white and black raisins was determined by Miletic et al. (2014) obtaining values of 5.6, 4.6, 4.0, and $1.7 \mathrm{mg} / \mathrm{g}$, respectively. These values were similar to those found in our work, except for the black raisins that were superior. Free phenolic contents for dry fruits were higher than those reported for in nature fruits, because the dehydration process concentrates the components in the matrices, which should also promote better protection of the tissue against fungal contamination (Boyjoo et al., 2017; Fabani et al., 2017). Although there are several studies that report the antifungal effect of phenolic compounds, and inhibition of mycotoxin production (Bolzan et al., 2015; Boyjoo et al., 2017; Pagnussatt et al., 2016), to date, there are no studies evaluating the relationship between their presence and the contamination with PAT in foods, especially in dry fruits.

\subsection{Correlation among contaminant and functional components in dry fruits}

In order to verify the degree of correlation between the main composition variables and PAT levels found in dry fruits samples, the Pearson correlation coefficient $(\mathrm{P})$ was estimated between PAT and the variables of sugar, soluble pectin, insoluble pectin, phenolic content, and ergosterol (Table 5). The sugars and the different fractions of pectin were chosen because they are a source of energy for the fungal development. The phenolic contents were chosen because they act as possible protectors against fungal contamination. The ergosterol was chosen as being indicative of fungal contamination. The results highlighted in bold are related to the significant correlations, considering a level of significance of $15 \%$. This level was selected because we are working with trace contaminants.

Table 4. Physical-chemical characterization of dehydrated fruits.

\begin{tabular}{lccccccc}
\hline \multicolumn{1}{c}{ Sample } & Quantity & $\mathrm{pH}$ & Acidity (\%) & Moisture (\%) & Total Sugars (\%) & Soluble Pectin (\%) & Insoluble Pectin (\%) \\
\hline Plum & 7 & $3.7-4.0$ & $0.6-1.5$ & $33.5-51.1$ & $2.0-3.5$ & $1.4-7.2$ & $16.7-37.3$ \\
Apricot & 3 & $4.1-4.1$ & $1.1-1.3$ & $26.1-28.8$ & $1.3-2.2$ & $4.6-5.6$ & $20.4-27.4$ \\
Apple & 5 & $4.0-5.4$ & $0.5-1.3$ & $7.3-21.9$ & $2.1-5.8$ & $1.4-7.4$ & $16.1-28.7$ \\
White grape & 3 & $4.1-4.2$ & $0.9-1.0$ & $17.1-22.9$ & $1.3-4.7$ & $1.5-2.3$ & $14.9-16.5$ \\
Black grape & 5 & $3.8-4.2$ & $0.4-1.0$ & $16.4-20.1$ & $3.6-5.5$ & $0.1-3.5$ & $9.9-24.4$ \\
\hline
\end{tabular}

Table 5. Pearson correlation between variables and occurrence of PAT.

\begin{tabular}{lccccc}
\hline \multicolumn{1}{c}{ Sample } & Sugar & Soluble pectin & Insoluble pectin & Phenolic content & Ergosterol \\
\hline Plum & $-0.51(\mathrm{p}: 0.23)$ & $\mathbf{0 . 7 4}(\mathrm{p}: \mathbf{0 . 0 6})$ & $\mathbf{0 . 6 2}(\mathrm{p}: \mathbf{0 . 1 3})$ & $-0.27(\mathrm{p}: 0.55)$ & $-0.11(\mathrm{p}: 0.79)$ \\
Apricot & $0.16(\mathrm{p}: 0.89)$ & $\mathbf{- 0 . 9 7 ( p : 0 . 1 4 )}$ & $\mathbf{0 . 9 9}(\mathbf{p}: \mathbf{0 . 0 8})$ & $\mathbf{0 . 9 9}(\mathbf{p}: \mathbf{0 . 0 6})$ & $\mathbf{0 . 9 8}(\mathbf{p}: \mathbf{0 . 1 1})$ \\
Apple & $\mathbf{- 0 . 7 3 ( p : 0 . 1 5 )}$ & $-0.68(\mathrm{p}: 0.20)$ & $-0.38(\mathrm{p}: 0.52)$ & $-\mathbf{0 . 7 2}(\mathbf{p}: \mathbf{0 . 1 5})$ & $-0.76(\mathrm{p}: 0.16)$ \\
White grape & $-0.14(\mathrm{p}: 0.90)$ & $-0.92(\mathrm{p}: 0.25)$ & $-0.92(\mathrm{p}: 0.25)$ & $-0.44(\mathrm{p}: 0.70)$ & $0.24(\mathrm{p}: 0.85)$ \\
Black grape & $0.57(\mathrm{p}: 0.30)$ & $-0.62(\mathrm{p}: 0.26)$ & $-0.11(\mathrm{p}: 0.85)$ & $0.44(\mathrm{p}: 0.45)$ & $0.48(\mathrm{p}: 0.40)$ \\
Fruits $^{*}$ & $\mathbf{- 0 . 6 6}(\mathrm{p}: \mathbf{0 . 1 4})$ & $\mathbf{0 . 7 8}(\mathrm{p}: \mathbf{0 . 0 6})$ & $0.24(\mathrm{p}: 0.64)$ & $\mathbf{- 0 . 6 3}(\mathbf{p}: \mathbf{0 . 1 5})$ & $\mathbf{0 . 9 9}(\mathbf{p}<\mathbf{0 . 0 0 1})$ \\
\hline
\end{tabular}

Values expressed as value of $\mathrm{R}$ (value of $\mathrm{p}) .{ }^{\star}$ Average for all the fruits. 
Pearson correlation among the different dry fruit samples showed that white and black raisins did not possess a significant correlation with PAT occurrence. The prune samples showed a positive correlation with the different pectin fractions (soluble and insoluble), with 0.74 (p: 0.06) and 0.62 (p: 0.13), respectively. The apricot samples showed almost perfect positive correlation with the variables of insoluble pectin, phenolic content, and ergosterol and almost a perfect negative correlation with soluble pectin.

The correlations with pectin fractions indicate that their components may have different degrees of methoxylation and that these affected the pectin availability for fungal metabolism (Chong et al., 2010). Candied fruit samples showed a positive correlation only with ergosterol and apple samples, while the correlation was negative with sugars and phenolic content. However, the matrix effect and low recovery on PAT determination did not allow a secure inference about relation between the contaminant and the chemical components in these samples.

In order to elucidate the global correlation between dry fruits and the composition variables chosen for the study, the Pearson analysis was performed for all the samples used in the study, using the average of each variable, except the candied fruit samples.

The sugar content of the samples was negatively correlated with the PAT $(-0.66)$, as well as the phenolic content $(-0.63)$. This reinforces the idea that phenolic compounds can contribute as a defence mechanism against pathogens, limiting their growth or the manifestation of their toxigenic potential (Boyjoo et al., 2017; Pagnussatt et al., 2016). The soluble pectin content also showed positive correlation with PAT levels (0.78). It suggests that the microorganism could not use this carbohydrate as an energy source and this may promote stress and, as a consequence, manifestation of toxigenic potential. This behaviour indicates that despite the studies suggesting pectin is an interferent for PAT determination (Katerere et al., 2008) our adapted method was efficient to eliminate this effect.

Ergosterol and PAT showed a high and significant correlation (0.99), therefore the determination of ergosterol could become promising to infer PAT contamination in dry fruit samples. This fact is in agreement with the studies carried out by Kadakal et al. (2005) which showed that PAT and ergosterol were indicative of microbiological quality in fruits.

\section{Conclusion}

The dry fruits analysed are sources of functional compounds, however they also can be a source of fungal contaminants, such as the PAT and ergosterol levels detected. Apricot samples stand out by their mycotoxin contamination. Pearson's correlation suggests that phenolic compounds may protect the fruits against the manifestation of the toxigenic potential of fungi that contaminate dry fruits. To prevent exposure of the population to the toxic effects of PAT, it would be interesting to adopt legal maximum limits for patulin on fruits other than apples before claiming them to be a source of functional compounds.

\section{Acknowledgements}

The authors acknowledge the financial support and fellowships granted by the Brazilian agencies CAPES and CNPq. L. Kupski received a postdoctoral fellowship by $\mathrm{CNPq}$ (438450/2016-7).

\section{References}

Alves, I., Oliveira, N., Laires, A., Rodrigues, A., \& Rueff, J. (2000). Induction of micronuclei and chromosomal aberrations by the mycotoxin patulin in mammalian cells: role of ascorbic acid as a modulator of patulin clastogenicity. Mutagenesis, 15(3), 229-234. http://dx.doi.org/10.1093/mutage/15.3.229. PMid:10792015.

Anastassiades, M., Lehotay, S. J., Štajnbaher, D., \& Schenck, F. J. (2003). Fast and easy multiresidue method employing acetonitrile extraction/partitioning and "dispersive solid-phase extraction" for the determination of pesticide residues in produce. Journal of AOAC International, 86(2), 412-431. PMid:12723926.

Association of Official Analytical Chemists - AOAC. (2000). Official methods of analysis of AOAC International. Arlington: AOAC.

Azaiez, I., Giusti, F., Sagratini, G., Mañes, J., \& Fernández-Franzón, M. (2014). Multi-mycotoxins analysis in dried fruit by LC/MS/MS and a modified QuEChERS procedure. Food Analytical Methods, 7(4), 935-945. http://dx.doi.org/10.1007/s12161-013-9785-3.

Bolzan, C. M., Caldas, S. S., Soares, B. M., \& Primel, E. G. (2015). Dispersive liquid-liquid microextraction for the preconcentration of multiple classes of pesticides in water. Analytical Letters, 48(17), 2754-2772. http://dx.doi.org/10.1080/00032719.2015.1048351.

Boyjoo, Y., Sun, H., Liu, J., Pareek, V. K., \& Wang, S. (2017). A review on photocatalysis for air treatment: From catalyst development to reactor design. Chemical Engineering Journal, 310, 537-559. http:// dx.doi.org/10.1016/j.cej.2016.06.090.

Busca, G., Berardinelli, S., Resini, C., \& Arrighi, L. (2008). Technologies for the removal of phenol from fluid streams: a short review of recent developments. Journal of Hazardous Materials, 160(2-3), 265-288. http://dx.doi.org/10.1016/j.jhazmat.2008.03.045. PMid:18455866.

Bustos, Y., Vaca, M., López, R., Bandala, E., Torres, L., \& Rojas-Valencia, N. (2014). Disinfection of primary municipal wastewater effluents using continuous UV and ozone treatment. Journal of Water Resource and Protection, 06(1), 2014. http://dx.doi.org/10.4236/ jwarp.2014.61003.

Caldas, S. S., Gonçalves, F. F., Primel, E. G., Prestes, O. D., Martins, M. L., \& Zanella, R. (2011). Principais técnicas de preparo de amostra para a determinação de resíduos de agrotóxicos em água por cromatografia líquida com detecção por arranjo de diodos e por espectrometria de massas. Quimica Nova, 34(9), 1604-1617. http:// dx.doi.org/10.1590/S0100-40422011000900021.

Caldas, S. S., Rombaldi, C., Arias, J. L., Marube, L. C., \& Primel, E. G. (2016). Multi-residue method for determination of 58 pesticides, pharmaceuticals and personal care products in water using solvent demulsification dispersive liquid-liquid microextraction combined with liquid chromatography-tandem mass spectrometry. Talanta, 146, 676-688. http://dx.doi.org/10.1016/j.talanta.2015.06.047. PMid:26695317.

Capello, C., Fischer, U., \& Hungerbühler, K. (2007). What is a green solvent? A comprehensive framework for the environmental assessment of solvents. Green Chemistry, 9(9), 927-934. http:// dx.doi.org/10.1039/b617536h.

Chandra, S., Sharma, R., Singh, K., \& Sharma, A. (2013). Application of bioremediation technology in the environment contaminated with 
petroleum hydrocarbon. Annals of Microbiology, 63(2), 417-431. http://dx.doi.org/10.1007/s13213-012-0543-3.

Chen, B., Wu, F., Wu, W., Jin, B., Xie, L., Feng, W., \& Ouyang, G. (2016). Determination of 27 pesticides in wine by dispersive liquid-liquid microextraction and gas chromatography-mass spectrometry. Microchemical Journal, 126, 415-422. http://dx.doi.org/10.1016/j. microc.2015.11.003.

Chen, C., Wei, L., Guo, X., Guo, S., \& Yan, G. (2014). Investigation of heavy oil refinery wastewater treatment by integrated ozone and activated carbon -supported manganese oxides. Fuel Processing Technology, 124, 165-173. http://dx.doi.org/10.1016/j.fuproc.2014.02.024.

Chenna, M., Messaoudi, K., Drouiche, N., \& Lounici, H. (2016). Study and modeling of the organophosphorus compound degradation by photolysis of hydrogen peroxide in aqueous media by using experimental response surface design. Journal of Industrial and Engineering Chemistry, 33, 307-315. http://dx.doi.org/10.1016/j. jiec.2015.10.016.

Chisvert, A., Benedé, J. L., Anderson, J. L., Pierson, S. A., \& Salvador, A. (2017). Introducing a new and rapid microextraction approach based on magnetic ionic liquids: Stir bar dispersive liquid microextraction. Analytica Chimica Acta, 983, 130-140. http://dx.doi.org/10.1016/j. aca.2017.06.024. PMid:28811019.

Chong, M. N., Jin, B., Chow, C. W. K., \& Saint, C. (2010). Recent developments in photocatalytic water treatment technology: a review. Water Research, 44(10), 2997-3027. http://dx.doi.org/10.1016/j. watres.2010.02.039. PMid:20378145.

Ciegler, A., Beckwith, A., \& Jackson, L. K. (1976). Teratogenicity of patulin and patulin adducts formed with cysteine. Applied and Environmental Microbiology, 31(5), 664-667. PMid:1275488.

DuBois, M., Gilles, K. A., Hamilton, J. K., Rebers, P. A., \& Smith, F. (1956). Colorimetric method for determination of sugar and related substances. Analytical Chemistry, 28(3), 350-356. http://dx.doi. org/10.1021/ac60111a017.

Economou, A., Botitsi, H., Antoniou, S., \& Tsipi, D. (2009). Determination of multi-class pesticides in wines by solid-phase extraction and liquid chromatography-tandem mass spectrometry. Journal of Chromatography. A, 1216(31), 5856-5867. http://dx.doi.org/10.1016/j. chroma.2009.06.031. PMid:19560776.

European Comission. (2006, March 9). Commission Regulation (EC) $\mathrm{n}^{\circ}$ 401/2006 of 23 February 2006 laying down the methods of sampling and analysis for the official control of the levels of mycotoxins in foodstuffs. Official Journal of the European Union.

Fabani, M. P., Baroni, M. V., Luna, L., Lingua, M. S., Monferran, M. V., Paños, H., Tapia, A., Wunderlin, D. A., \& Feresin, G. E. (2017). Changes in the phenolic profile of Argentinean fresh grapes during production of sun-dried raisins. Journal of Food Composition and Analysis, 58, 23-32. http://dx.doi.org/10.1016/j.jfca.2017.01.006.

Freitas, R. F., Schrack, E. C., He, Q., Silliman, B. R., Furlong, E. B., Telles, A. C., \& Costa, C. S. (2016). Consumer control of the establishment of marsh foundation plants in intertidal mudflats. Marine Ecology Progress Series, 547, 79-89. http://dx.doi.org/10.3354/meps11624.

Gutarowska, B., \& Zakowska, Z. (2009). Mathematical models of mycelium growth and ergosterol synthesis in stationary mould culture. Letters in Applied Microbiology, 48(5), 605-610. http:// dx.doi.org/10.1111/j.1472-765X.2009.02577.x. PMid:19291213.

Iha, M. H., \& Sabino, M. (2008). Incidence of patulin in Brazilian apple-based drinks. Food Control, 19(4), 417-422. http://dx.doi. org/10.1016/j.foodcont.2007.05.001.

Ji, X., Li, R., Yang, H., Qi, P., Xiao, Y., \& Qian, M. (2017). Occurrence of patulin in various fruit products and dietary exposure assessment for consumers in China. Food Control, 78, 100-107. http://dx.doi. org/10.1016/j.foodcont.2017.02.044.

Kadakal, Ç., Nas, S., \& Ekıncı, R. (2005). Ergosterol as a new quality parameter together with patulin in raw apple juice produced from decayed apples. Food Chemistry, 90(1-2), 95-100. http://dx.doi. org/10.1016/j.foodchem.2004.03.030.

Katerere, D. R., Stockenström, S., \& Shephard, G. S. (2008). HPLCDAD method for the determination of patulin in dried apple rings. Food Control, 19(4), 389-392. http://dx.doi.org/10.1016/j. foodcont.2007.04.015.

Kupski, L., \& Badiale-Furlong, E. (2015). Principal components analysis: An innovative approach to establish interferences in ochratoxin A detection. Food Chemistry, 177, 354-360. http://dx.doi.org/10.1016/j. foodchem.2015.01.005. PMid:25660897.

Lee, S. J., Umano, K., Shibamoto, T., \& Lee, K. G. (2005). Identification of volatile components in basil (Ocimum basilicum L.) and thyme leaves (Thymus vulgaris L.) and their antioxidant properties. Food Chemistry, 91(1), 131-137. http://dx.doi.org/10.1016/j.foodchem.2004.05.056.

Liu, B.-H., Yu, F.-Y., Wu, T.-S., Li, S.-Y., Su, M.-C., Wang, M.-C., \& Shih, S.-M. (2003). Evaluation of genotoxic risk and oxidative DNA damage in mammalian cells exposed to mycotoxins, patulin and citrinin. Toxicology and Applied Pharmacology, 191(3), 255-263. http://dx.doi.org/10.1016/S0041-008X(03)00254-0. PMid:13678658.

Miletic, N., Popovic, B., Mitrovic, O., Kandic, M., \& Leposavic, A. (2014). Phenolic compounds and antioxidant capacity of dried and candied fruits commonly consumed in Serbia. Czech Journal of Food Sciences, 32(4), 360-368. http://dx.doi.org/10.17221/166/2013-CJFS.

Murillo-Arbizu, M., Amézqueta, S., González-Peñas, E., \& de Cerain, A. L. (2009). Occurrence of patulin and its dietary intake through apple juice consumption by the Spanish population. Food Chemistry, 113(2), 420-423. http://dx.doi.org/10.1016/j.foodchem.2008.07.054.

Osswald, H., Frank, H., Komitowski, D., \& Winter, H. (1978). Longterm testing of patulin administered orally to Sprague-Dawley rats and Swiss mice. Food and Cosmetics Toxicology, 16(3), 243-247. http://dx.doi.org/10.1016/S0015-6264(76)80520-2. PMid:689579.

Pagnussatt, F. A., de Lima, V. R., Dora, C. L., Costa, J. A. V., Putaux, J. L., \& Badiale-Furlong, E. (2016). Assessment of the encapsulation effect of phenolic compounds from Spirulina sp LEB-18 on their antifusarium activities. Food Chemistry, 211, 616-623. http://dx.doi. org/10.1016/j.foodchem.2016.05.098. PMid:27283675.

Rogatsky, E., \& Stein, D. (2005). Evaluation of matrix effect and chromatography efficiency: new parameters for validation of method development. Journal of the American Society for Mass Spectrometry, 16(11), 1757-1759. http://dx.doi.org/10.1016/j.jasms.2005.07.012. PMid:16198119.

Scaglioni, P. T., Souza, T. D., Schmidt, C. G., \& Badiale-Furlong, E. (2014). Availability of free and bound phenolic compounds in rice after hydrothermal treatment. Journal of Cereal Science, 60(3), 526532. http://dx.doi.org/10.1016/j.jcs.2014.08.005.

Smith, E. E., Duffus, E. A., \& Small, M. H. (1993). Effects of patulin on postimplantation rat embryos. Archives of Environmental Contamination and Toxicology, 25(2), 267-270. http://dx.doi. org/10.1007/BF00212140. PMid:8368869.

Souza, M. M., Recart, V. M., Rocha, M., Cipolatti, E. P., \& Badiale-Furlong, E. (2009). Estudo das condições de extração de compostos fenólicos de cebola (Allium cepa L.). Revista do Instituto Adolfo Lutz, 2, 26-34.

Speijers, G., Franken, M., \& Van Leeuwen, F. (1988). Subacute toxicity study of patulin in the rat: effects on the kidney and the gastrointestinal tract. Food and Chemical Toxicology, 26(1), 23-30. http:// dx.doi.org/10.1016/0278-6915(88)90037-3. PMid:3345966. 
Sweeney, M. J., \& Dobson, A. D. (1998). Mycotoxin production by Aspergillus, Fusarium and Penicillium species. International Journal of Food Microbiology, 43(3), 141-158. http://dx.doi.org/10.1016/ S0168-1605(98)00112-3. PMid:9801191.

Welke, J. E., Hoeltz, M., Dottori, H. A., \& Noll, I. B. (2009). Effect of processing stages of apple juice concentrate on patulin levels. Food Control, 20(1), 48-52. http://dx.doi.org/10.1016/j. foodcont.2008.02.001.
Wichmann, G., Herbarth, O., \& Lehmann, I. (2002). The mycotoxins citrinin, gliotoxin, and patulin affect interferon $-\gamma$ rather than interleukin-4 production in human blood cells. Environmental Toxicology, 17(3), 211-218. http://dx.doi.org/10.1002/tox.10050. PMid:12112629.

Zouaoui, N., Sbaii, N., Bacha, H., \& Abid-Essefi, S. (2015). Occurrence of patulin in various fruit juice marketed in Tunisia. Food Control, 51, 356-360. http://dx.doi.org/10.1016/j.foodcont.2014.09.048. 